Superalloys 2012: $12^{\text {th }}$ International Symposium on Superalloys

\title{
Secondary Creep of Thin-Walled Specimens Affected by Oxidation
}

\author{
Matthias Bensch ${ }^{1}$, Ernst Fleischmann ${ }^{1}$, Christian H. Konrad ${ }^{1}$, Markus Fried ${ }^{2}$, Catherine M. F. Rae ${ }^{3}$ and Uwe Glatzel ${ }^{1}$ \\ ${ }^{1}$ Metals and Alloys, University of Bayreuth, Ludwig-Thoma-Str. 36b, 95447 Bayreuth, Germany \\ ${ }^{2}$ MTU Aero Engines GmbH, Dachauer Str. 665, 80995 Munich, Germany \\ ${ }^{3}$ Department of Materials Science and Metallurgy, University of Cambridge, Pembroke Street, Cambridge CB2 3QZ, U.K.
}

Keywords: Nickel-base Superalloy, Creep, Oxidation affected $\gamma^{\prime}$-fraction, thin-walled

\section{Abstract}

The creep behavior of thin-walled specimens cannot be assumed to be as uniform as for thick-walled specimens. The difference is attributed to the influence of oxidation. Oxidation tests have been carried out on single crystal nickel-based superalloy M247LC SX specimens with different thicknesses down to $0.1 \mathrm{~mm}$. The results show that the $\gamma^{\prime}$-volume fraction is strongly affected by oxidation in near surface regions. Depletion of the aluminium reservoir required to establish a protective alumina scale causes the change. Based on these results five single crystal nickel-based superalloys with different compositions have been cast. These alloys represent different near surface regions within an oxidation affected specimen. Creep tests on single crystals of these alloys have been performed to quantify the influence of different $\gamma^{\prime}$-volume fractions on secondary creep. The stress dependence was fit to the Norton creep law and the exponent $n$, exhibited sigmoidal behavior as a function of the $\gamma^{\prime}$-fraction, almost doubling at $50 \%$ volume fraction. This behavior suggests a change in the dominant creep mechanism. These results are essential for modeling and predicting the creep properties of thin-walled specimens in turbine blade applications.

\section{Introduction}

The weight reduction of fast rotating parts in turbine engines, such as blades, results in a concomitant weight saving in the turbine disk, shaft, bearings and casing. This leads to a useful increase in the thrust to weight ratio of the turbine engine. Therefore, knowledge of the high temperature mechanical properties of thin-walled specimens plays an important role in the optimization of turbine efficiency. The industrial drive to reduce the thickness of fast-rotating turbine blades is documented by several patents [1-4]. However several investigations [5-11] have discovered significant differences in the high temperature mechanical properties between thick and thin specimens. Some of these authors [7-11] attribute this difference to environmental factors such as high temperature oxidation. It has been shown in several publications [11-19], that oxidation has a strong influence on the microstructure of nickel-based superalloys. This leads, for example, to the formation of a $\gamma^{\prime}$-free layer just below the oxide film [11,16]. Dryepondt et al. [11] demonstrate that the formation of a $\gamma^{\prime}$-free layer is not, in itself, sufficient to explain the discrepancy in creep properties between thin and thick specimens. The longer-range diffusion of alloying components from the interior towards the oxidized surface alters the alloy composition
[18] and changes the $\gamma^{\prime}$-fraction over a much wider section. As $\gamma^{\prime}$ precipitates are essential for improved creep behavior and the $\gamma^{\prime}$-fraction strongly influences creep behaviour [12-15], thin-walled specimens are likely to be affected not only by a $\gamma^{\prime}$-free layer, but also by a much wider layer where the $\gamma^{\prime}$ is reduced [16]. The present work concentrates on the effect of the oxidation-modified $\gamma^{\prime}$-volume fraction on secondary creep. This is essential to our understanding of the effect of oxidation on creep properties as a function of thickness in the $\gamma^{\prime}$-reduced and depleted layers. These correlations are important for the design and optimization of superalloy parts.

\section{Oxidation tests}

Material and experimental procedure

To investigate the oxidation performance of M247LC SX, specimens of three different thicknesses have been prepared from a bar using electrical wire discharge machining (EDM). These samples have been vibration ground with SiC-paper (1200 grid) to thicknesses of $1.0 \mathrm{~mm}, 0.3 \mathrm{~mm}$ and $0.1 \mathrm{~mm}$. The initial alloy composition was measured and the composition of matrix and $\gamma^{\prime}$-phase were calculated using ThermoCalc software [21] and the TTNi7 [22] database, see Table 1.

The ground and cleaned (ultrasonic bath with acetone) specimens were isothermally or cyclically oxidized for $100 \mathrm{~h}$ in a preheated furnace at $980^{\circ} \mathrm{C}$. For the cyclic oxidation tests the specimens were placed in an alumina crucible. The crucible was attached to a lift using a platinum wire enabling the time and placement in the preheated furnace to be controlled automatically. The following oxidation profile was chosen: $1 \mathrm{~h}$ holding time in the preheated furnace followed by a 5 min cooling period. Temperature measurements revealed a cooling rate of $80^{\circ} \mathrm{C}$ per second in the relevant high temperature oxidation temperature range. Using the described cyclic profile the oxidation time of $100 \mathrm{~h}$ corresponds to 100 cycles.

\section{Microstructure investigations of the oxidized specimens}

The results of energy dispersive X-ray spectroscopy (EDS) and X-ray diffraction (XRD) measurements show that M247LC SX generates a sequence of four oxide layers with the following compositions: Top oxide layer: $\mathrm{NiO}$, second oxide layer: $\mathrm{CoCr}_{2} \mathrm{O}_{4}$, third oxide layer: $\alpha-\mathrm{Al}_{2} \mathrm{O}_{3}, \mathrm{HfO}_{2}, \mathrm{TiO}, \mathrm{Ta}_{2} \mathrm{O}_{5}$, $\mathrm{TiTaO}_{4}$, bottom oxide layer: $\alpha-\mathrm{Al}_{2} \mathrm{O}_{3}$.

Tab. 1: Nominal and measured compositions [wt. \%] of M247LC SX and computed compositions [wt. \%] of matrix and $\gamma^{\prime}$-phase using ThermoCalc [21] and TTNi7 [22].

\begin{tabular}{|ccccccccccc|}
\hline & $\mathrm{Al}$ & $\mathrm{C}$ & $\mathrm{Co}$ & $\mathrm{Cr}$ & $\mathrm{Hf}$ & $\mathrm{Mo}$ & $\mathrm{Ta}$ & $\mathrm{Ti}$ & $\mathrm{W}$ & $\mathrm{Ni}$ \\
\hline M247LC SX (nominal) & 5.7 & 0.07 & 9.3 & 8.1 & 1.4 & 0.5 & 3.3 & 0.7 & 9.4 & (bal.) \\
M247LC SX (measured) & 5.8 & 0.07 & 9.3 & 8.1 & 1.4 & 0.5 & 3.3 & 0.7 & 9.4 & (bal.) \\
matrix (calc.) & 3.2 & 0.0003 & 13.3 & 14.6 & 0.4 & 0.8 & 0.7 & 0.2 & 11.6 & (bal.) \\
$\gamma^{\prime}$-phase (calc.) & 7.8 & 0 & 6.1 & 2.9 & 2.0 & 0.2 & 5.3 & 1.1 & 7.6 & (bal.) \\
\hline
\end{tabular}


To measure the $\gamma^{\prime}$-phase fraction scanning electron microscope (SEM) images were recorded from different positions parallel to the oxidized surface of the rectangular specimens, see Fig. 1a). Since the specimens had different initial thicknesses, the mirror plane indicated by the dashed-dotted line in Fig. 1 has been chosen as the origin $(d=0 \mu \mathrm{m})$ for the measurements that follow. The areas examined lie at different distances $d$ from the mirror plane of the rectangular specimen. Images have been recorded from the polished but non-etched specimens (Fig. 1a), using the quadrant back scattering detector (QBSD) in a Zeiss 1540 ESB field emission SEM.

The recorded images (Fig. $1 \mathrm{~b}-\mathrm{d}$ ) were binarized, the $\gamma^{\prime}$-fraction was determined for each image and the mean value calculated for all images at identical distances from the mirror plane.

The microstructural investigations show, that the $\gamma^{\prime}$ precipitates change in shape and size with distance from the mirror plane. Fig. 1b) - d) show the shape of the $\gamma^{\prime}$ precipitates changing from cubic (Fig. 1d) at the position the mirror plane $(d=0 \mu \mathrm{m})$ to spherical (Fig. 1b) near the transition from $\gamma^{\prime}$-reduced to $\gamma^{\prime}$-free layer.
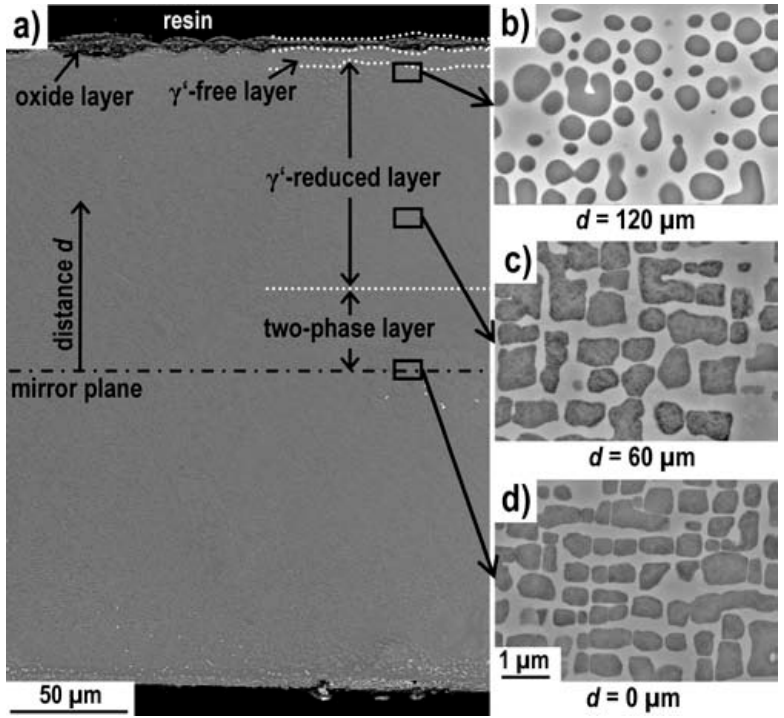

Fig. 1: SEM-image of the cross-section (a) of an oxidized $0.3 \mathrm{~mm}$ rectangular specimen. The sample has been isothermally oxidized for $100 \mathrm{~h}$ at $980^{\circ} \mathrm{C}$ in a preheated furnace. The images b) $-\mathrm{d}$ ) show the matrix $/ \gamma^{\prime}$ microstructure in dependence of the distance $d$ to the mirror plane.

The measured $\gamma^{\prime}$-volume fraction as a function of the distance $d$ to the mirror plane is presented in Fig. 2. The results of oxidation tests under isothermal conditions are shown in Fig. 2a) and under cyclic conditions in Fig. 2b).

They reveal that, in addition to the formation of a $\gamma^{\prime}$-free layer, a much thicker layer of about $200 \mu \mathrm{m}$ exists with a reduced $\gamma^{\prime}$-fraction. For the $0.1 \mathrm{~mm}$ specimen the depletion reaches the centre with a reduction of the $\gamma^{\prime}$-fraction from $59 \%$ to $30 \%$. Comparing isothermal with cyclic oxidation the $\gamma^{\prime}$-fraction distributions show significant differences. For the $1.0 \mathrm{~mm}$ cyclic oxidized specimen the oxidation-influenced regions are broader and show a more pronounced $\gamma^{\prime}$ loss. The $0.3 \mathrm{~mm}$ cyclic oxidized specimen shows a $10 \%$ lower $\gamma^{\prime}$-fraction than the isothermally oxidized $0.3 \mathrm{~mm}$ specimen. These investigations are in good agreement with the results reported for René N5 [16].

a)

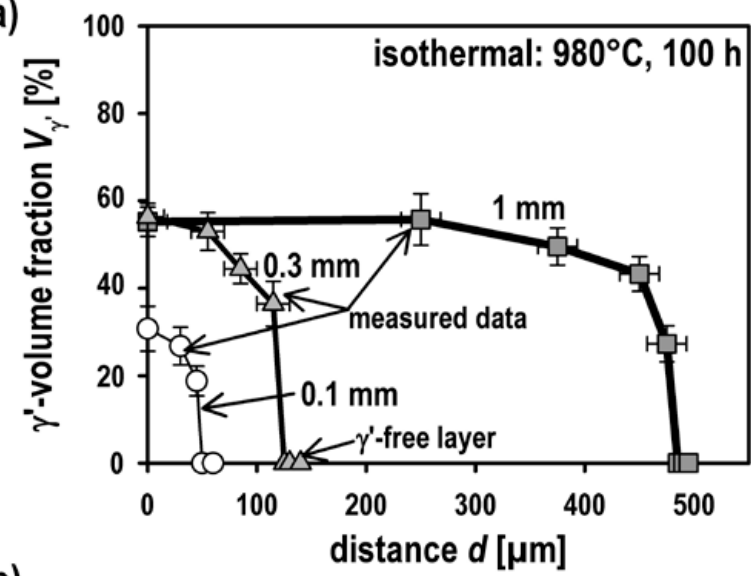

b)

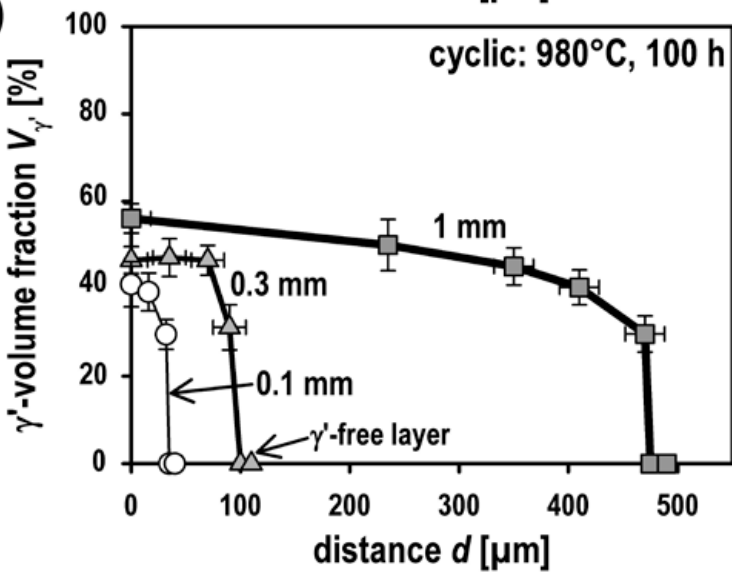

Fig. 2: Measured $\gamma^{\prime}$-volume fraction $V_{\gamma^{\prime}}$ in dependence of the distance $d$ to the mirror plane. The analyzed specimens have been (a) isothermally or (b) cyclic oxidized for $100 \mathrm{~h}$ at $980^{\circ} \mathrm{C}$. The initial specimen thickness varies between $1.0 \mathrm{~mm}$ (thick lines with squares), $0.3 \mathrm{~mm}$ (lines with triangles) and $0.1 \mathrm{~mm}$ (hairlines with circles).

Using a series of EDS-linescans consisting of 200 measurements, the chemical composition of a $0.3 \mathrm{~mm}$ specimen oxidized for $100 \mathrm{~h}$ at $980^{\circ} \mathrm{C}$ (Fig. 1) was analyzed. The measured compositions as a function of the distance to the mirror plane are listed in Table 2. The results show that there is a strong concentration gradient between the mirror plane and the near-surface regions. The EDS measurements reveal a significant depletion of aluminum, tantalum and hafnium in the surface-near regions. In contrast, cobalt, chromium and tungsten show enrichment from the mirror plane to surface. The comparison of the composition of M247LC SX with M247ox-0\% and the calculated M247LC SX matrix (Tab. 1) shows a similar trend but with different levels of impact. A much lower content of the $\gamma^{\prime}$-phase forming element aluminium (1 compared to 3.2 wt. \% ) and a very high content of the solid solution hardening element tungsten (15 compared to 11.7 wt. \% ) is observed for the $\gamma^{\prime}$-free layer in contrast to M247LC SX matrix. 
Tab. 2: Measured compositions [wt. \%] of different regions within an oxidized $0.3 \mathrm{~mm}$ specimen (Fig. 1) in dependence of the distance $d$ to mirror plane. The specimen has been oxidized for $100 \mathrm{~h}$ at $980^{\circ} \mathrm{C}$ in ambient air. Using ThermoCalc [21] and TTNi7 [22] the solidus $T_{\text {sol }}$ and liquidus $T_{\text {liq }}$ temperatures have been calculated for casting the different single crystals named by and initial alloy M247LC SX and the measured $\gamma^{\prime}$-volume fraction $V_{\gamma}$,.

\begin{tabular}{|ccccccccccccc|}
\hline Alloy & $\mathrm{Al}$ & $\mathrm{Co}$ & $\mathrm{Cr}$ & $\mathrm{Hf}$ & $\mathrm{Mo}$ & $\mathrm{Ni}$ & $\mathrm{Ta}$ & $\mathrm{Ti}$ & $\mathrm{W}$ & $T_{\text {sol }}\left[{ }^{\circ} \mathrm{C}\right]$ & $T_{\text {liq }}\left[{ }^{\circ} \mathrm{C}\right]$ & $d[\mu \mathrm{m}]$ \\
\hline M247ox-62\% & 5.8 & 9.2 & 8.2 & 1.4 & 0.6 & 60.9 & 3.2 & 0.7 & 10 & 1292 & 1371 & $0-10$ \\
M247ox-56\% & 5.2 & 8.7 & 7.4 & 1.4 & 0.6 & 60.9 & 3.3 & 0.9 & 11.6 & 1298 & 1379 & $60-70$ \\
M247ox-49\% & 4.6 & 9.0 & 8.2 & 0.8 & 0.6 & 60.1 & 3.5 & 0.8 & 12.4 & 1318 & 1386 & $100-110$ \\
M247ox-23\% & 2.5 & 10.2 & 10.3 & 0.3 & 0.7 & 58.6 & 2.5 & 0.6 & 14.3 & 1364 & 1411 & $120-130$ \\
M247ox-0\% & 1.0 & 10.6 & 10.7 & 0 & 0.7 & 60.7 & 1.0 & 0.3 & 15.0 & 1421 & 1436 & $130-140$ \\
\hline
\end{tabular}

\section{Creep tests of single crystal alloys with different oxidation affected $\gamma^{\prime}$-fractions}

Material and experimental procedure

The alloy compositions listed in Table 2 were selected as representing the different regions of an oxidation affected thin-walled specimen. To facilitate casting for each alloy the liquidus $T_{\text {liq }}$ and solidus $T_{\text {sol }}$ temperature has been computed using ThermoCalc [21] and TTNi7 [22]. Subsequently, the alloys will be denoted as M247ox-62\% to M247ox-0\%. The designation of each alloy is composed of the name of the initial alloy M247LC SX and the measured $\gamma^{\prime}$-volume fraction after oxidation (Tab. 2). The name M247ox corresponds to an oxidized M247 alloy with a certain $\gamma^{\prime}$-volume fraction. Therefore M247ox-62\% is the composition of M247LC SX (except C) and M247ox-0\% the composition of the $\gamma^{\prime}$-free layer. Note, that the composition of the $\gamma^{\prime}$-free layer represented by M247ox-0\% differs significantly from the matrix composition of M247LC SX (Tab. 1). In contrast to M247LC SX carbon has been set to zero for all M247ox alloys listed in Table 2.

Single Crystal (SX) Casting

Prior to SX casting the alloys were arc-melted from pure elements with a purity higher than $99.9 \%$. All samples were produced in a proprietary vacuum investment casting furnace, described in [23]. For the production of single crystals the furnace was equipped with a chill-plate and a baffle according to the Bridgeman-process. The mould temperature was $1490^{\circ} \mathrm{C}$ which is at least $50^{\circ} \mathrm{C}$ above the melting temperature of the alloys. With this setup a temperature gradient of $6^{\circ} \mathrm{C} / \mathrm{mm}$ is achieved. The melt was superheated to $100^{\circ} \mathrm{C}$ above the computed liquidus temperature $T_{\text {liq }}$ (Tab. 2) controlled by type $S$ thermocouple to fully homogenize it. The ceramic molds used in this work were manufactured with a crystal selector. The innermost layer is built up of colloidal silica bound $\mathrm{ZrSiO}_{4}$ with additions of $\mathrm{CoAl}_{2} \mathrm{O}_{4}$ for a good surface quality. The consecutive layers consisted of $\mathrm{Al}_{2} \mathrm{O}_{3}$ with different particle sizes also bound with colloidal silica. The withdrawal speed was set to $3 \mathrm{~mm} / \mathrm{min}$.

All alloys were subjected to the same heat treatment $\left(1230^{\circ} \mathrm{C} / 2 \mathrm{~h}\right.$, raised to $1280^{\circ} \mathrm{C}$ at $1^{\circ} \mathrm{C} / \mathrm{min}, 1280^{\circ} \mathrm{C} / 2 \mathrm{~h}$, $1080^{\circ} \mathrm{C} / 4 \mathrm{~h}, 870^{\circ} \mathrm{C} / 20$ ) as published by Magadi et al. [24].

\section{Creep test}

Creep tests are performed at $980^{\circ} \mathrm{C}$ at stress levels from $50 \mathrm{MPa}$ up to $230 \mathrm{MPa}$ in a creep test facility described in [25].

To minimize the influence of oxidation, creep tests have been carried out in vacuum at constant load. Using the creep test facility a vacuum of $2 \cdot 10^{-7} \mathrm{mbar}$ is reached after an evacuation period of at least $12 \mathrm{~h}$.

Creep tests were carried out with $80 \mathrm{~mm}$ flat specimens eroded out of the cylindrical cast and heat-treated rods by electrical wire discharge machining (EDM). Eight creep samples have been prepared from each rod.
The geometry of the creep specimens has four small ridges at the centre of the specimen. These ridges mark the gauge section with a volume of $6.3 .1 \mathrm{~mm}^{3}$ and are essential for creep strain measurements with a video extensometer [25]. The specimen axis of all specimens was within $5^{\circ}$ to the $<001>$ crystal orientation except to M247ox-62\%, which has an angular misalignment of $20^{\circ}$.

Before creep testing the specimen surface was ground using SiCpaper down to 1200 grit finish and cleaned thoroughly in an ultrasonic bath with acetone.

Experimental results

Microstructure of heat-treated SX alloys with varying $\gamma^{\prime}$-fractions SEM images of the un-etched matrix/ $\gamma^{\prime}$-microstructure of single crystal alloys M247ox with measured $\gamma$ '-volume fraction $V_{\gamma}$, are shown in Fig. 3.
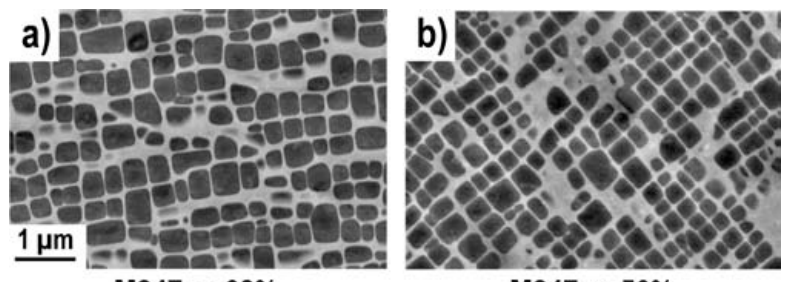

M2470x-62\%

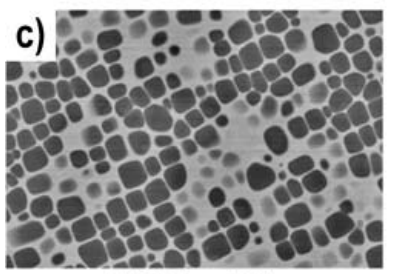

M247ox-49\%
M247ox-56\%

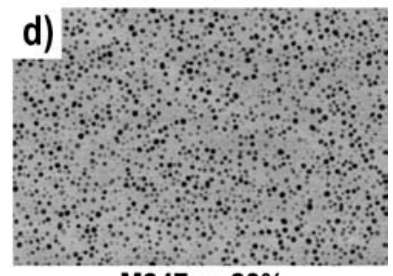

M2470x-23\%

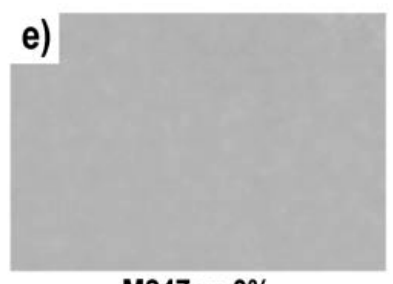

\section{M247ox-0\%}

Fig. 3: SEM images (QBSD-detector) of the un-etched matrix/ $\gamma^{\prime}$-microstructure of the casted and heat-treated single crystal nickel-based superalloys denoted as M247ox alloys. All images show the microstructure in the same magnification. The image plane is perpendicular to the load axis of the creep experiments. 
The matrix $/ \gamma^{\prime}$-microstructure of M247ox-62\% corresponding to M247LC SX shows a regular cubic structure of the $\gamma^{\prime}$ precipitates with a $\gamma^{\prime}$-volume fraction $V_{\gamma^{\prime}}$ of $62 \%$. This is in very good agreement with the determined $\gamma^{\prime}$-volume fraction of M247LC SX $\left(\mathrm{V}_{\gamma^{\prime}}=61 \%\right)$ within the material scatter. The chemical composition of the $\gamma^{\prime}$-free layer is represented by M247ox- $0 \%$ alloy. For M247ox- $0 \%$ no precipitation of the $\gamma^{\prime}$ phase can be observed. The images of Fig. 3 reveal, that for the microstructures of the M247ox alloys two additive effects exists:

From M247ox-62\% to M247ox-0\% a continuous reduction of the $\gamma^{\prime}$-fraction can be observed. This is accompanied by a size reduction from the cubic-shaped $\gamma^{\prime}$ precipitates (Fig. 3a) to finely distributed spherical $\gamma^{\prime}$ precipitates (Fig. 3d).

Microstructure of M247ox alloys after creep experiment

The microstructure of the two-phase M247ox alloys after creep at $980^{\circ} \mathrm{C}$ and $150 \mathrm{MPa}$ in dependence of the $\gamma^{\prime}$-volume fraction is shown in Fig. 4.

The alloy with the highest $\gamma^{\prime}$-fraction of $62 \%$ (Fig. 4a) shows a structure consisting of highly orientated rafted $\gamma^{\prime}$ with high aspect ratio. As Fig. 4b) shows, a reduction in $V_{\gamma^{\prime}}$ down to $56 \%$ results in the formation of less well oriented and coarsened $\gamma^{\prime}$. A comparison of the microstructures of M247ox-62\% with M247ox$49 \%$ reveals that similar, but finer microstructures were formed. The alloy with $V_{\gamma^{\prime}}=23 \%$ (Fig. 4d) shows only a slightly distortion of the initially spherical-shaped $\gamma^{\prime}$-phase (Fig. 3d).

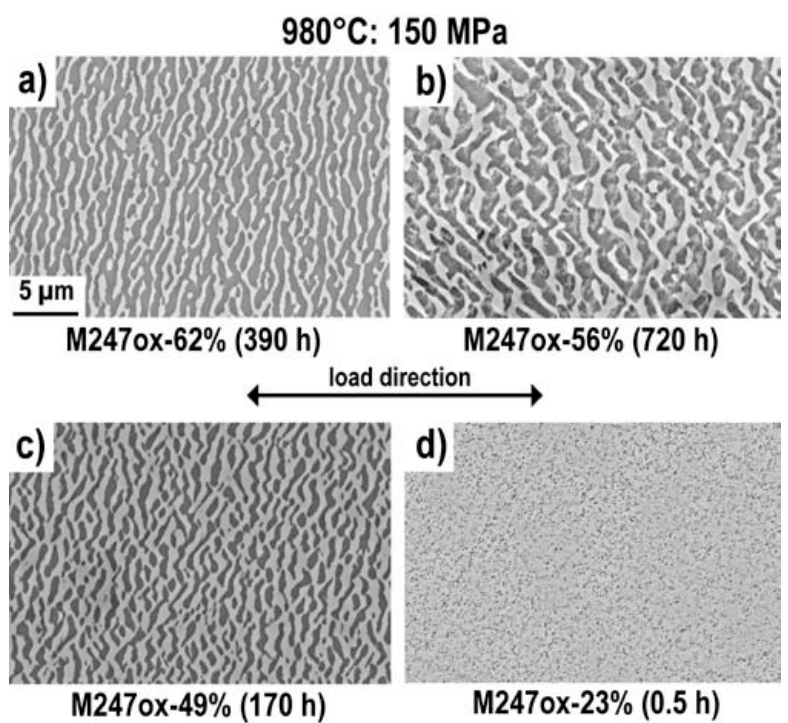

Fig. 4: SEM images (QBSD-detector) of the matrix/ $\gamma^{\prime}$ microstructures of the two-phase M247ox alloys after creep deformation at $980^{\circ} \mathrm{C}$ with an initial stress of $150 \mathrm{MPa}$ and a horizontal load axis. The darker phase represents the $\gamma$ '-phase. All images show the microstructure in the same magnification. The parenthesized values indicate the creep rupture life time.

To check whether the finely distributed spherical shaped $\gamma^{\prime}$ precipitates of alloy M247ox-23\% dissolves at elevated temperatures or not, a sample has been heat-treated at $1000^{\circ} \mathrm{C}$ for an exposure time of $5 \mathrm{~h}$ and quenched down in liquid gallium in order to freeze in the observed microstructure. Using this technique a cooling rate of $10^{4} \mathrm{C} / \mathrm{s}$ is reached. From the metallographic investigations only a slightly decrease of $\gamma^{\prime}$-volume fraction was observed $-18 \%$ in comparison to initially $23 \%$. This is within the material scatter. We conclude that $\gamma^{\prime}$-phase is not dissolved at $1000^{\circ} \mathrm{C}$ in alloy M247ox-23\%.

Creep test results

Creep curves resulting from the creep tests performed at $980^{\circ} \mathrm{C}$ at different stress levels (50-230 $\mathrm{MPa}$ ) in vacuum are presented in Fig. 5. The results are plotted by $\gamma^{\prime}$-volume fraction from $62 \%$ (Fig. 5a) to 0\% (Fig. 5e). Each image shows the logarithm of the creep rate against the creep strain.

The results show that a reduction of the $\gamma^{\prime}$-fraction increases the creep rate strongly.
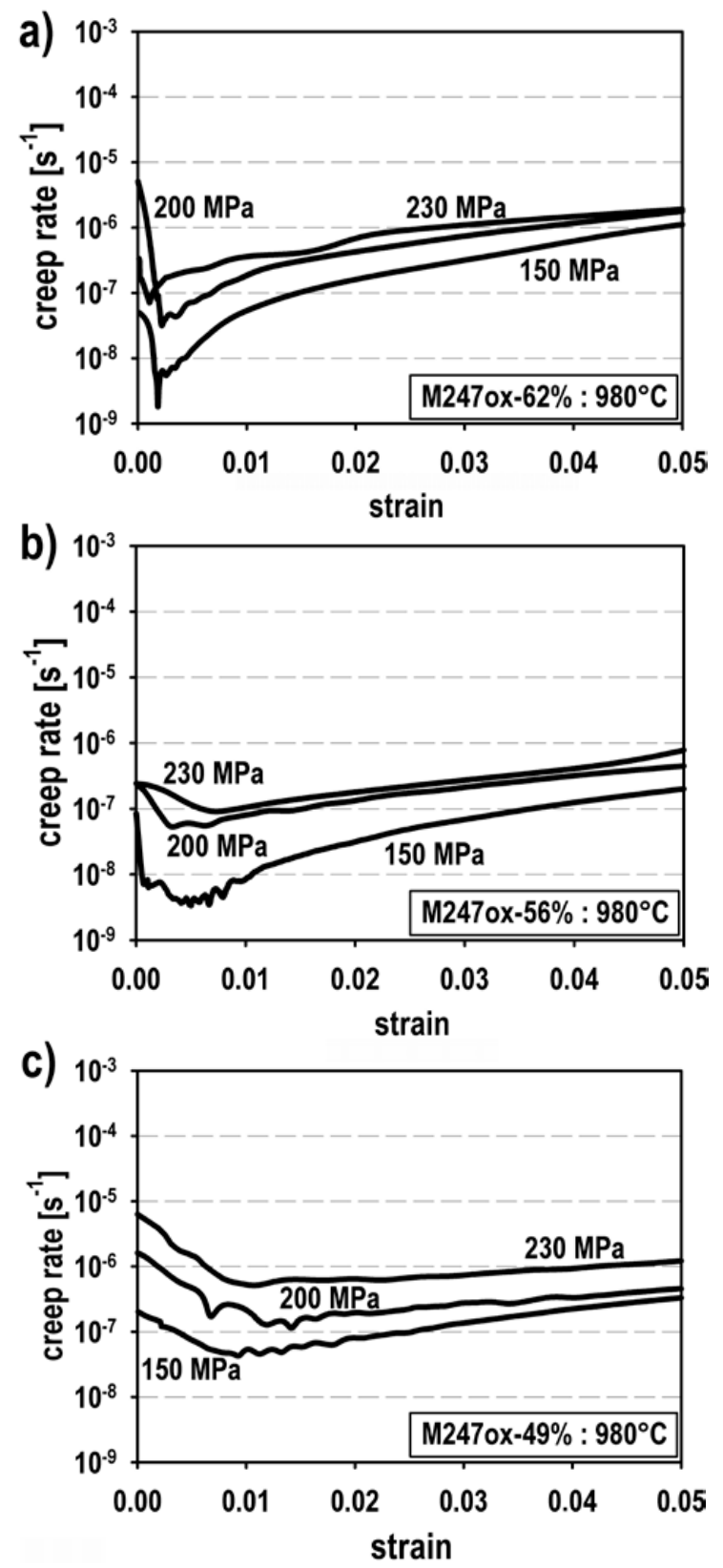

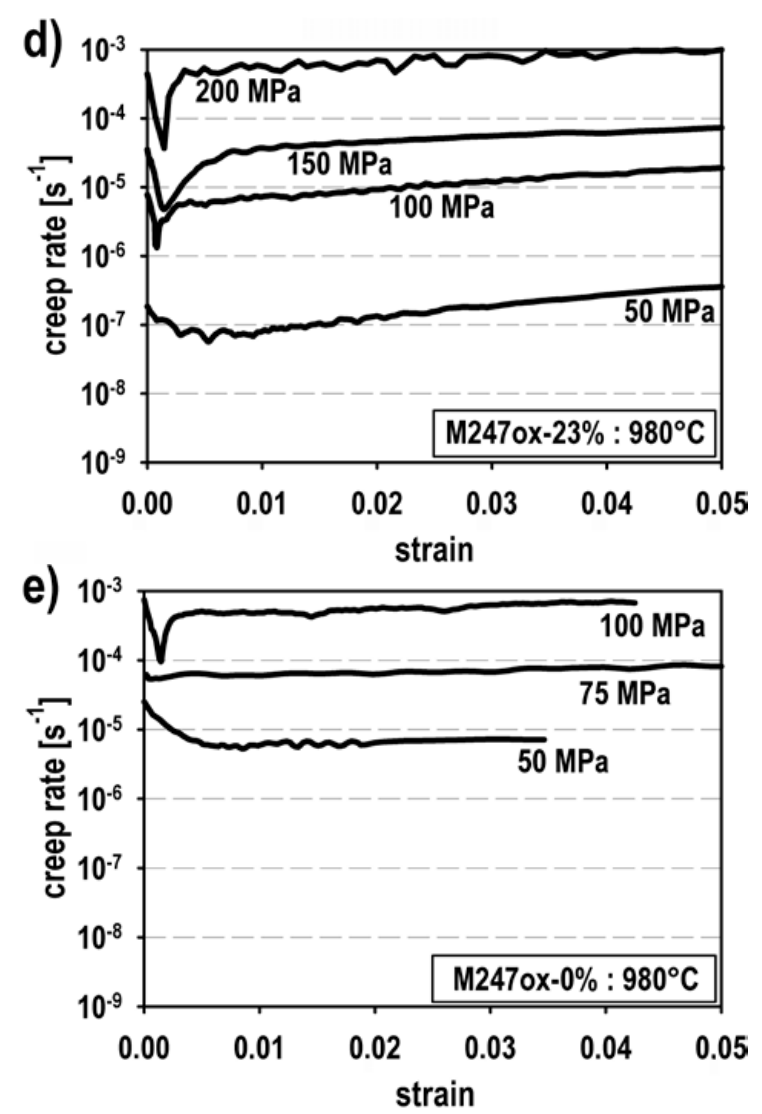

Fig. 5: Results of creep experiments performed at $980^{\circ} \mathrm{C}$ at different stress levels (50-230 MPa) in vacuum. In each image the creep behavior of the alloy with the same indicated $\gamma^{\prime}$-volume fraction is plotted. The $\gamma^{\prime}$-volume fraction reduces from $62 \%$ (a) down to $0 \%$ (e)

Further creep tests have been carried out on M247ox-0\% representing the composition of the $\gamma^{\prime}$-free layer of an oxidized M247LC SX specimen. The experiments have been performed at $1100^{\circ} \mathrm{C}$ and at different stress levels (20, 40 and $60 \mathrm{MPa}$ ) in vacuum. The creep curves are presented in Fig. 6.

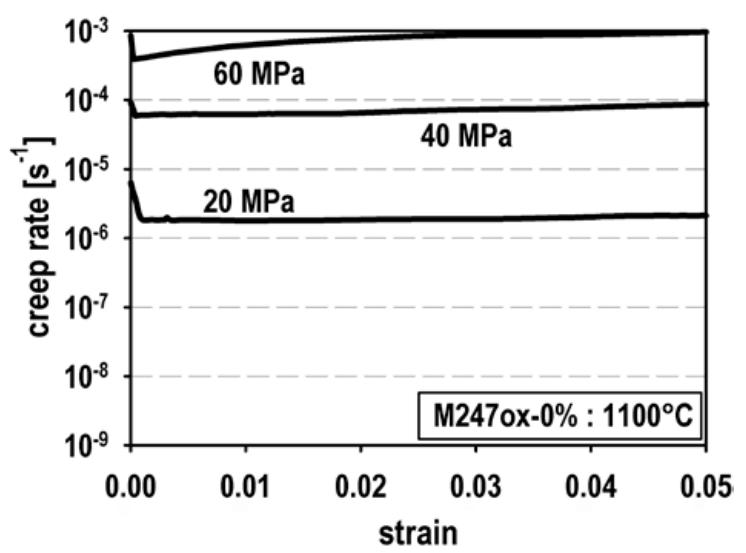

Fig. 6: Creep curves of the $\gamma^{\prime}$-free alloy M247ox-0\% tested at $1100^{\circ} \mathrm{C}$ at different stress levels in vacuum.
Using the creep behavior at $980^{\circ} \mathrm{C}$ and $1100^{\circ} \mathrm{C}$ an activation energy $Q$ of $362 \mathrm{~kJ} \mathrm{~mol}^{-1}$ was determined for the $\gamma^{\prime}$-free alloy M247ox-0\%.

We used a slightly modification of Norton creep law [20] for constant temperature:

$$
\dot{\varepsilon}_{\min }=A^{*}\left(\frac{\sigma}{\sigma_{0}}\right)^{n}
$$

with a medium stress load of $\sigma_{0}=100 \mathrm{MPa}$.

In Fig. 7 the minimum creep rate is plotted versus the initial stress level in a double logarithmic scale. The Norton exponent $n$ (Eq. 1) is extracted from the resulting slope for each alloy. The Norton exponents vary from a maximum of $n_{\mathrm{M} 247 \mathrm{ox}-62 \%}=8.7$ for the $62 \%$ volume fraction alloy to $n_{\mathrm{M} 2470 \mathrm{x}-0 \%}=4.1$ for the $\gamma^{\prime}$-free alloy.

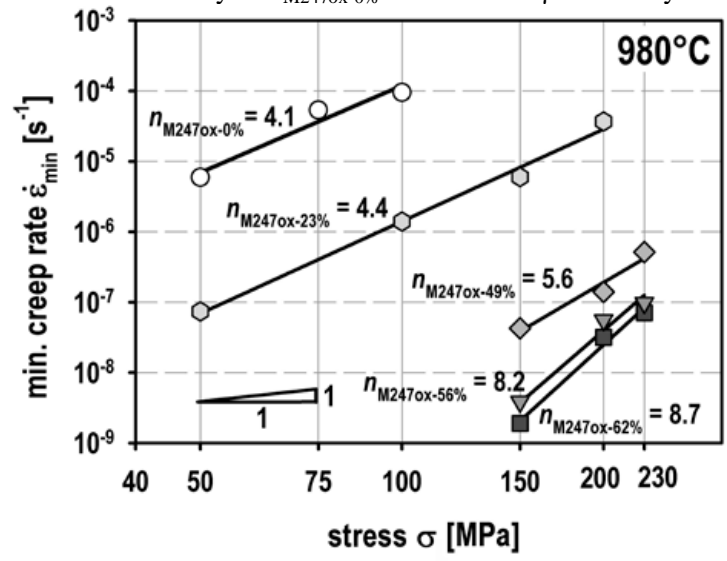

Fig. 7: From creep experiments at $980^{\circ} \mathrm{C}$ (Fig. 5) determined minimum creep rates in dependence of the applied stress. The Norton exponent $n$ of each M247ox alloy has been extracted from the slope of the regression curve.

The results of Norton exponent $n$ and prefactor $A^{*}$ are shown as a function of $\gamma^{\prime}$-volume fraction in Fig. 8. The Norton exponent $n$ exhibits a s-shaped behaviour in dependence of the $\gamma^{\prime}$-volume fraction with a sharp drop from higher than 8 down to 5 at 55\% $\gamma^{\prime}$-volume fraction.

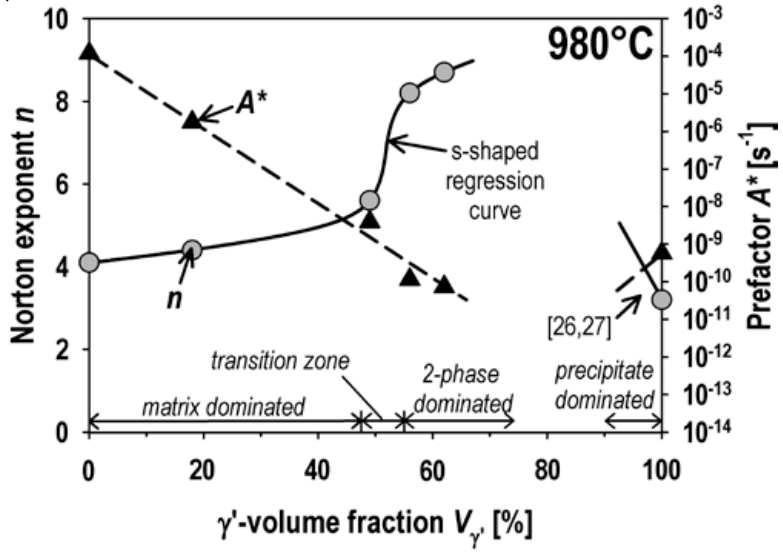

Fig. 8: Experimentally determined Norton exponents $n$ (grey circles) and constant $A^{*}$ (black triangles) as a function of the $\gamma^{\prime}$-volume fraction. Data for $100 \% \gamma^{\prime}$-phase are taken from literature [26,27]. The value of $A^{*}$ gives the minimum creep rate for a stress of $100 \mathrm{MPa}$. 
The behavior of $\mathrm{n}$ for $\gamma^{\prime}$-volume fractions higher than $62 \%$ has not been considered, since this work focuses on the oxidation affected area resulting in a reduction of $\gamma^{\prime}$-volume fraction. However, published data suggests that the Norton exponent will eventually drop down to 3.2 for $100 \% \gamma^{\prime}$-phase [26,27]. $A^{*}$ increases from $7 \cdot 10^{-10} \mathrm{~s}^{-1}$ for $62 \% \gamma^{\prime}$-volume fraction slightly to $10^{-4} \mathrm{~s}^{-1}$.

\section{Discussion}

Fig. 9 shows the minimum creep rates determined from creep experiments of M247ox alloys at $980^{\circ} \mathrm{C}$ in vacuum against the $\gamma^{\prime}$-volume fraction. The solid black lines with white symbols represent the minimum creep rates for different stress levels. For all investigated stresses a very strong influence of the $\gamma^{\prime}$-volume fraction is observed. Below a $\gamma^{\prime}$-volume fraction of $40 \%$ the curves have similar slopes.

Only Murakumo et al. [13,14] show creep data for $\gamma^{\prime}$-volume fractions higher than $62 \%$. Considering differences in the alloy compositions and test parameters, the comparison of the presented creep results with literature shows a similar dependency of minimum creep rate in dependence of the determined $\gamma^{\prime}$-volume fraction.

Two conclusions can be drawn from comparison with this data: 1) the influence of the oxidation-affected $\gamma^{\prime}$-volume fraction on creep properties shows a comparable dependency to other nickel-based superalloys; 2) the measured creep behavior of the M247ox alloys represents a valid database to determine the Norton exponent $n$ dependence of the $\gamma^{\prime}$-volume fraction.

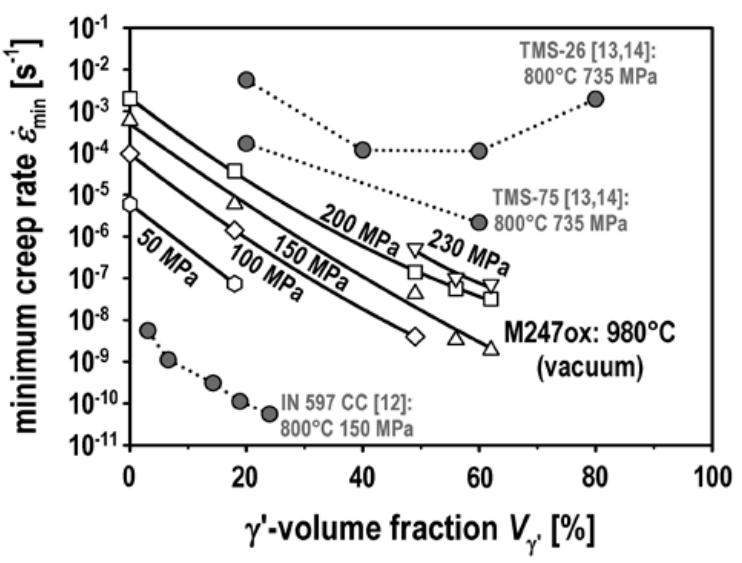

Fig. 9: Determined minimum creep rates extracted from creep tests at $980^{\circ} \mathrm{C}$ on M247ox alloys in dependence of the $\gamma^{\prime}$-volume fraction. The data are compared with published values from Gibbons et al. [12] and Murakumo et al. $[13,14]$

The experimentally-determined Norton exponent $n$ shows a sharp drop from $>8$ for $\gamma^{\prime}$-volume fractions of $55 \%$ and above, down to about 5 for $V_{\gamma^{\prime}}<49 \%$. This dependence can be attributed to a change in the creep mechanism [28]. For $\gamma^{\prime}$-volume fractions $V_{\gamma^{\prime}}>55 \%$ present in the most advanced nickel-based superalloys, $\gamma^{\prime}$ precipitate hardening dominates the creep properties.

Lower $\gamma^{\prime}$-volume fractions with similar $\gamma^{\prime}$ cube edge length $l_{\gamma^{\prime}}$ result in a reduced matrix channel thickness $l_{\text {matrix }}$, see Eq. 2 .

$$
l_{\text {matrix }}=l_{\gamma^{\prime}}\left(V_{\gamma^{\prime}}^{-\frac{1}{3}}-1\right)
$$

As Fig. 3 reveals, a change in size and fraction of the $\gamma^{\prime}$ precipitate is accompanied by a change in the matrix channel thickness.

For small precipitates and very low $\gamma^{\prime}$-volume fractions $\left(V_{\gamma^{\prime}} \sim 5 \%\right)$ the creep deformation is dominated by weakly-coupled dislocations [29] cutting the ordered $\gamma^{\prime}$ precipitates in a disordered matrix. For larger $\gamma^{\prime}$ precipitates and higher $\gamma^{\prime}$-volume fractions $\left(V_{\gamma^{\prime}}>5 \%\right)$ cutting by strongly-coupled dislocations [30] pairs becomes relevant. For thin matrix channels and high $\gamma^{\prime}$-volume fractions $\left(V_{\gamma^{\prime}}>50 \%\right)$ by-pass mechanism by Orowan bowing can be assumed as dominating mechanism.

The $\gamma^{\prime}$-phase is the major influence on the yield stress over a wide range of volume fractions and the relationship between the two is well explored [30]. However the effect of $\gamma^{\prime}$ volume fraction on the Norton exponent has not previously been considered. Daehn and Brehm [31] argue that the value of $n=5$ commonly observed in a wide range of alloys can be attributed to the maintenance of a steady-state network of dislocations by balancing dislocation multiplication with diffusion controlled climb. As the stress rises the dislocation density rises as well as dislocation velocity to give rapidly rising creep rates. The results presented here suggest that at $\gamma^{\prime}$-volume fractions below $50 \%$ the dislocations are weakly or strongly coupled as pairs cutting the $\gamma^{\prime}$ and the dislocation density is determined by the longer-range networks of dislocations as in many alloys. However as the $\gamma^{\prime}$-volume fraction increases above $50 \%$, the dislocation movement becomes restricted to the narrow $\gamma$ channels and the density is governed by the local conditions in the channels. Norton creep exponents in high volume fraction superalloys such as CMSX-4 are typically much higher than conventional value of 4-6; values as high as 13 have been measured at the somewhat lower temperature of $850^{\circ} \mathrm{C}$ [32].

Based on the measurements of $\gamma^{\prime}$-fraction (Fig. 1) and the creep behavior of the various alloys, (Fig. 8), the minimum creep rate can be calculated as a function of the distance $d$. A medium stress level of $100 \mathrm{MPa}$ has been chosen to illustrate this. Fig. 10 shows that oxidation affects the total creep rate of thin specimens very significantly. Defining a load bearing creep range from $10^{-10}-10^{-8} \mathrm{~s}^{-1}$ it can be seen, that the bearing cross section reduces strongly with decreasing specimen thickness for very thin specimens of $0.1 \mathrm{~mm}$.

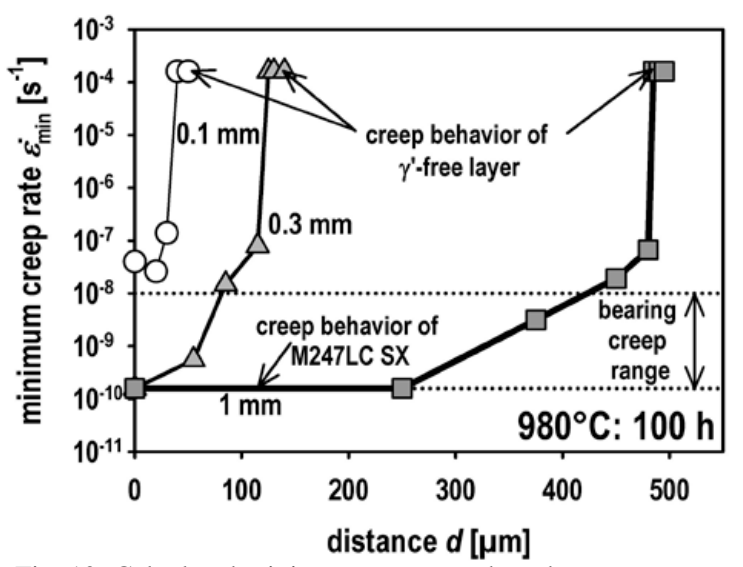

Fig. 10: Calculated minimum creep rate based on creep test results (Fig. 5) as a function of the distance to the mirror plane $d$ of isothermally oxidized $\left(980^{\circ} \mathrm{C}, 100 \mathrm{~h}\right)$ specimens with different thicknesses. 
We can use the Equation 1 to assess the load-bearing capability of the three thin sections as a function of the strain rate. By dividing the samples into incremental sections of volume fractions $62 \%$, $56 \%, 49 \%, 23 \%$ and $0 \%$, the stress to produce a fixed strain rate in each section can be calculated from Equation 1. The measured values of $A^{*}$ and $n$ for each volume fraction are taken from Figure 8, the stress on each section is calculated and these are averaged over the whole sample by estimating the fraction of the cross section occupied by each of the volume fractions above. The results are plotted in Figure 11 together with the stress for the unoxidized sample with the full volume fraction throughout. This shows that, for instance, at a strain rate of $10^{-8} \mathrm{~s}^{-1}$, the stress drops from $176 \mathrm{MPa}$ to $159 \mathrm{MPa}$ for the $1 \mathrm{~mm}$ section, $126 \mathrm{MPa}$ for the $0.3 \mathrm{~mm}$ section and $62 \mathrm{MPa}$ for the $0.1 \mathrm{~mm}$ section; a percentage change of $89 \%, 71 \%$ and $35 \%$ respectively.

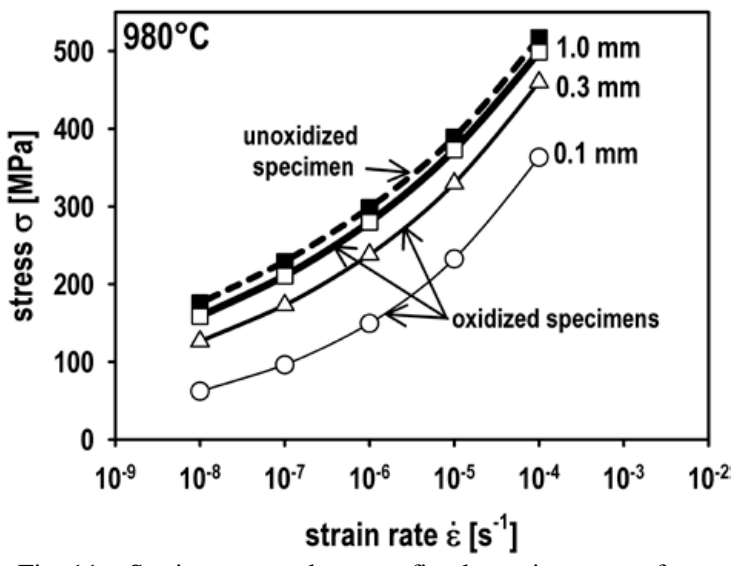

Fig. 11: Strain to produce a fixed strain rate of an unoxidized specimen (black squares with dashed line) and of oxidized specimens (white symbols with solid lines) with different thicknesses indicated by different line thicknesses.

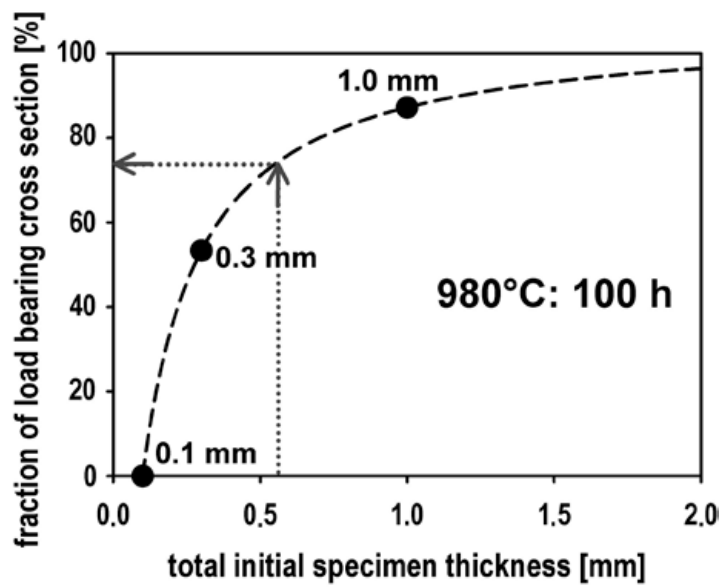

Fig. 12: Loss of the load bearing cross section after an oxidation time of $100 \mathrm{~h}$ at $980^{\circ} \mathrm{C}$ in ambient air in dependence of the initial total specimen thickness.

The strong influence of microstructure change as function of specimen thickness can be seen in Fig. 12 for an oxidation time of $100 \mathrm{~h}$ at $980^{\circ} \mathrm{C}$. As the main influence of oxidation occurs in the first few hours before a continuous and dense oxide scale forms, the presented curve gives a qualitative insight into the reduction of load bearing cross section for shorter oxidation times. For longer exposure times the curve will move only slightly to the right as the dense oxide scale already formed protects the sample from further rapid oxidation. A similar oxidation affected microstructure has been observed for several nickel-based superalloys. Recent observations on René N5 [16] show a similar substrate reaction due to oxidation. It can be assumed that the loss in creep properties can be transferred to other alumina scale forming superalloys.

\section{Summary}

Oxidation strongly influences the volume fraction of $\gamma^{\prime}$ precipitates in surface-near regions. Both the nominal alloy composition and the alloying element distribution is strongly affected by the consumption of aluminium in forming the oxide scale. The influence of this on creep behavior increases with decreasing specimen thickness. Based on these results a series of single crystal nickel-based superalloys have been cast with composition replicating the different regions of the oxidationaffected substrate. These alloys, denoted as M247ox alloys, exhibit not only different chemical compositions but also different $\gamma^{\prime}$-volume fractions varying between $0 \%$ and $62 \%$. Creep experiments were carried out on these alloys. The results can be summarized as follows:

- the $\gamma^{\prime}$-volume fraction strongly influences minimum creep rate and creep rupture life;

- the Norton exponent $n$ shows a strong reduction with reduced $\gamma^{\prime}$-volume fraction attributed to change in mechanism from climb and cutting to by-pass mechanism;

- oxidation shows a strong influence on creep properties of thin-walled specimens, e.g. for $980^{\circ} \mathrm{C}$ and $100 \mathrm{~h}$ exposure time in air a significant reduction in load bearing cross section down to $50 \%$ and less is observed for thicknesses $\leq 0.3 \mathrm{~mm}$;

- Activation energy of $362 \mathrm{~kJ} \mathrm{~mol}^{-1}$ has been determined for creep of $\gamma^{\prime}$-free layer forming in surface-near regions of M247LC SX.

The measured relation between the oxidation-affected changes in $\gamma^{\prime}$-volume fraction and the identified influence on secondary creep stage enables a prediction of creep behavior of thin-walled specimens, relevant for thin cast volumes of creep loaded turbine blades.

\author{
References \\ [1] V. Chung et al., “Thin wall cooling system” (US Patent \\ 6478535 B1, 2002)
}

[2] Y. Shigemichi, "Thin-walled, lightweight cooled turbine blade” (US Patent 20040091360 A1, 2003).

[3] G. Liang, "Thin turbine rotor blade with sinusoidal flow cooling channels” (US Patent 7753650 B1, 2010).

[4] K.F. O'Connor: "Single-cast, high-temperature thin wall gas turbine component” (US Patent 5545003, 1996).

[5] V. Seetharaman and A.D. Cetel, "Thickness debit in creep properties of PWA 1484”, Superalloys 2004, ed. K.A. Green, T.M. Pollock, H. Harada, T.E. Howson, R.C. Reed, J.J. Schirra, and S. Walston, (Warrendale, PA, USA: The Metallurgical Society (TMS), 2004), 207-214. 
[6] B. Cassenti and A. Staroselsky, "The effect of thickness on the creep response of thin-wall single crystal components”, Mat. Sci. Eng., A508 (2009), 183-189.

[7] M. Doner and J.A. Heckler, "Effects of section thickness and orientation on creep rupture properties of two advanced single crystal alloys", in SAE Technical Paper 851785, (Society of Automotive Engineers Inc., 1985).

[8] M. Doner and J.A. Heckler, "Identification of mechanisms responsible degradation in thin-wall stress-rupture properties", Superalloys 1988, ed. D.N. Duhl, G. Maurer, S. Antolovich, C. Lund and S. Reichman. (Warrendale, PA, USA: TMS, 1988), 653-662.

[9] R. Hüttner, J. Gabel, R. Völkl and U. Glatzel, “Creep behavior of thick and thin walled structures of a single crystal nickel-base superalloy at high temperatures - experimental method and results", Superalloys 2008, ed. R.C. Reed, K.A. Green, P. Caron, T.P. Gabb, M.G. Fahrmann, E.S. Huron, S.R. Woodard. (Warrendale, PA, USA: The Metallurgical Society (TMS), 2008), 719-726.

[10] R. Hüttner, J. Gabel, U. Glatzel and R. Völkl, "First creep results on thin-walled single-crystal superalloys“, Mat. Sci. Eng. A, 510-511 (2009), 307-311.

[11] S. Dryepondt, D. Monceau, F. Crabos and E. Andrieu, "Static and dynamic aspects of coupling between creep behavior and oxidation on MC2 single crystal superalloy at $1150^{\circ} \mathrm{C}$ ", Acta Mater., 53 (2005), 4199-4209.

[12] T.B. Gibbons and B.E. Hopkins, "Creep behaviour and microstructure of Ni-Cr base alloys”, Metal Science, 18 (1984), 273-280.

[13] T. Murakumo, T. Kobayashi, Y. Koizumi and H. Harada, "Creep behaviour of Ni-base single-crystal superalloys with various $\gamma^{\prime}$ volume fractions”, Acta Mater., 52 (2004) 3737-3744.

[14] T. Murakumo, T. Kobayashi, Y. Koizumi and H. Harada, "Effect of $\gamma^{\prime}$ Volume Fraction for Creep Strength of Ni-Base Superalloys at $800^{\circ} \mathrm{C}$ ", Journal of Japan Institute of Metals, 69 (2005) 763-768.

[15] H. Harada, $\quad$ M. Yamazaki, Y. Koizumi, $\quad$ N. Sakuma, N. Furuya and H. Kamiya, "Alloy Design for nickel-base superalloys", High temperature alloys for gas turbines, ed. R. Brunetaud et al., (Liege, Belgium, 1982), 721-737.

[16] M. Bensch, J. Preussner, R. Hüttner, G. Obigodi, S. Virtanen, J. Gabel and U. Glatzel, "Modelling and analysis of the oxidation influence on creep behaviour of thin-walled structures of the single-crystal nickel-base superalloy René N5 at $980^{\circ} \mathrm{C}^{\prime}$, Acta Mater., 58 (2010), 1607-1617.

[17] D.P. Whittle, D.J. Evans, D.B. Scully and G.C. Wood, "Compositional changes in the underlying alloy during the protective oxidation of alloys”, Acta Metall., 15 (1967), 1421-1430.
[18] B.D. Bastow, D.P. Whittle and G.C. Wood, “Alloy Depletion Profiles Resulting from the Preferential Removal of the Less Noble Metal During Alloy Oxidation”, Oxid. Met., 12 (1978), 413-436.

[19] H.E. Evans, A.T. Donaldson and T.C. Gilmour, "Mechanisms of Breakaway Oxidation and Application to a Chromia-Forming Steel” Oxid. Met., 52 (1999),379-402.

[20] F.H. Norton, "Creep of Steel at High Temperatures", McGraw-Hill, New York (U.S.A.), (1929).

[21] ThermoCalc Version TCCR, ThermoCalc Software AB, Stockholm (Sweden), 2006.

[22] Thermotech Ni-based Superalloys Database, TTNI7, Version 7.0, Thermo-Calc Software AB, Stockholm (Sweden), 2006.

[23] C.H. Konrad， M. Brunner， K. Kyrgyzbaev， R. Völkl and U. Glatzel, "Determination of heat transfer coefficient and ceramic mold material parameters for alloy IN738LC investment castings", Journal of Materials Processing Technology, 211 (2011), 181-186

[24] G. Magadi and V.M. Radhakrishnan, "Creep deformation behavior and failure diagnostic diagrams of a columnar-grained nickel-based superalloy”, Journal of Materials Engineering and Performance, 13 (2004), 493-503.

[25] R. Völkl, D. Freund and B. Fischer, "Economic Creep Testing of Ultra-High Temperature Alloys", Journal of Testing and Evaluation, 31 (2003), 35-43.

[26] PA. Flinn, “Theory of Deformation in Superlattices”, Trans. Metal. Soc. AIME, 218 (1960), 145-155.

[27] R.K. Ham, R.H. Cook, G.R. Purdy and G. Willoughby, "The Influence of $\gamma^{\prime}$ Precipitation upon the Creep of $\gamma^{\prime}\left(\mathrm{Ni}_{3}(\mathrm{Al}, \mathrm{Ti})\right)$ Single Crystals”, Metal Science J., 6 (1972), 205-210.

[28] H.J. Frost and M.F. Ashby, "Deformation-Mechanism Maps: The Plasticity and Creep of Metals and Ceramics", Pergamon Press (1982).

[29] L.M. Brown and R.K. Ham, "Strengthening Mechanisms in Crystals”, Applied Science, London (U.K.) (1971).

[30] W. Huther and B. Reppich, "Interaction of Dislocations with coherent, stress-free, ordered particles”, Z. Metall., 69 (1978), 628-634.

[31] G.S. Daehm, H. Brehm, H. Lee and B.-S. Lim, “A model for creep based on microstructural length scale evolution". Mat. Sci. Eng., A 387-389, (2004), 576-584.

[32] G.L. Drew, R.C. Reed, K. Kakechi and C.M.F Rae, "Single crystal superalloys; the transition from primary to secondary creep”, Superalloys 2004, ed. K.A. Green, T.M. Pollock, H. Harada, T.E. Howson, R.C. Reed, J.J. Schirra, and S. Walston. (Warrendale, PA (USA): The Metallurgical Society (TMS), 2004), 127-136. 